\title{
Pengaruh Supervisi Pendidikan Dan Motivasi Kerja Terhadap Kinerja Guru Pada SMA Negeri 1 Makassar
}

\author{
The Effect of Educational Supervision and Work Motivation on Teacher Performance at \\ SMA Negeri 1 Makassar \\ Rahmaniah \\ *Email: rahmaniah@universitasbosowa.ac.id \\ ${ }^{1}$ Program Studi Sekolah Dasar Fakultas Keguruan Dan Ilmu Pendidikan Universitas Bosowa
}

Diterima: 14 September 2021 / Disetujui: 21 Desember 2021

\begin{abstract}
ABSTRAK
Kinerja guru dalam menjalankan tugasnya dipengaruhi oleh beberapa faktor yaitu Supervisi Pendidikan oleh kepala sekolah dan motivasi dalam bekerja. Penelitian ini bertujuan untuk mengetahui pengaruh Supervisi Pendidikan dan Motivasi Kerja terhadap Kinerja Guru SMA Negeri 1 Makassar. Penelitian ini termasuk dalam penelitian ex post facto dan bersifat kuantitatif. Jumlah sampel penelitian adalah seluruh populasi guru yang ada di SMA Negeri 1 Makassar yang berjumlah 64 guru. Teknik pengumpulan data dengan menggunakan kuisioner. Data yang terkumpul dianalisis secara kuantitatif. Hasil penelitian menunjukan kegiatan Supervisi Pendidikan yang dilakukan oleh kepala sekolah dan Motivasi Kerja Guru berpengaruh secara positif dan signifikan terhadap Kinerja Guru baik secara terpisah maupun secara simultan.
\end{abstract}

Kata Kunci: Supervisi Pendidikan, Motivasi Kerja, Kinerja Guru.

\section{ABSTRACT}

Teacher performance in carrying out their duties is influenced by several factors including teacher's work motivationandprincipal's education supervision. This research was conducted to determine the effect of education supervision and work motivation on Teacher Performance at SMA Negeri 1 Makassar. The research is categorized into ex post facto research and is quantitative in nature. The number of research samples is the entire population of 64 teachers in SMA Negeri 1 Makassar. Data collection techniques in this study using a questionnaire. The collected data is then analyzed quantitatively. The results show that principal's education supervision and the teacher's work motivation have a positive and significant impact on teacher performance, both separately and simultaneously.

Keywords: Educational Supervision, Work Motivation, Teacher Performance.

(c) $\underset{\mathrm{EY}}{(-)}$ This work is licensed under Creative Commons Attribut on License 4.0 CC-BY International license

\section{A. PENDAHULUAN}

Dalam pembukaan Undang Undang

Dasar 1945 alenia keempat dijelaskan bahwa salah satu hal penting tujuan dari pada dibentuknya Negara Indonesia adalah untuk mencerdaskan kehidupan bangsa. Untuk mencerdaskan kehidupan bangsa maka diperlukanlah pendidikan.
Pendidikan yang baik, akan mampu meningkatkan kualitas sumber daya manusia. Untuk meningkatkan kualitas sumber daya manusia seperti yang tertuang dalam undang undang nomor 20 Tahun 2003 tentang sistem pendidikan nasional harus didukung dengan peningkatan kualitas pendidik (Sisdiknas 2003). Sebab 
untuk mewujudkan sistem pendidikan nasional yang berkualitas, diperlukan tenaga kependidikan di dalamnya.

Guru merupakan salah satu faktor penting dalam menentukan kualitas pendidikan, bahkan menurut Olaleye dan Florance, guru merupakan penentu keberhasilan atau kegagalan suatu bangsa (2013) sebagai pendidik guru berperan aktif dalam mentransfer nilai-nilai sekaligus pembimbing dan menuntun siswa dalam belajar. Setidaknya terdapat sembilan belas peranan guru dalam kegiatan pembelajaran yaitu; guru sebagai pendidik, pengajar, pembimbing, pelatih, penasehat, inovator, suri tauladan, pembangkit pandangan, pekerja rutin, pembawa cerita, aktor, emansipator, evaluator, dan sebagai kulminator (Mulyasa dan Mukhlis 2007). Semua hal tersebut tidak bisa dilakukan bila guru tidak memiliki kualitas kinerja yang baik dalam mengajar. Peningkatan kualitas sistem pendidikan sangat dipengaruhi oleh kualitas kinerja guru sebagai agen pembelajaran di sekolah.

Sayangnya kualitas pendidikan di Indonesia masih jauh dari kata memuaskan survei kemampuan pelajar yang dirilis oleh Programme for International Student Assesment (PISA) pada Desember 2019 di Paris. Dalam survey tersebut, Indonesia berada di peringkat ke-72 dari 77 negara (Marie-Helene 2019). Berada di urutan ke ke-6 terbawah masih kalah dari negara tetangga seperti Malaysia dan Brunai Darussalam. Sementara itu, Education Index dari Human Development Reports (2017) menempatkan Indonesia di posisi ke-7 di ASEAN dengan skor 0,622. Di mana skor tertinggi diperoleh oleh Singapura (0,832), Malaysia (0,719), Brunai Darussalam (0,704). Data UNESCO dalam Global Education Monitoring (GEM) Report 2016 menempatkan kualitas guru di Indonesia berada di urutan ke-14 dari 14 negara berkembang. Artinya sebagian besar kualitas kinerja guru di Indonesia masih belum optimal dalam melaksanakan kegiatan mengajar. Upaya peningkatan kualitas pendidikan dengan meningkatkan kualitas kinerja guru menjadi salah satu prioritas lembaga pendidikan di Indonesia, salah satunya adalah SMA Negeri 1 Makassar.

SMA Negeri 1 Makassar merupakan salah satu SMA unggulan di kota Makassar. Berdasarkan hasil akreditasi dari Badan Akreditasi Nasional Sekolah Madrasah (BAN SM), SMA Negeri 1 Makassar memiliki akreditasi A. Hal tersebut menunjukan bahwa pemenuhan delapan komponen akreditasi yang 
meliputi standar isi, standar proses, standar kompetensi lulusan, standar pendidik dan kependidikan. Standar sarana dan prasarana, standar pengelolaan, standar pembiayaan dan standar penilaian pendidikan sudah dilakukan dengan baik. Di tahun 2020, misalnya, SMA Negeri 1 Makassar berhasil menghantarkan siswanya sebanyak 103 siswa lulus masuk PTN dimana mereka tersebar di kampus favorit di Indonesia seperti Universitas Hasanudin, Universitas Negeri Makassar, Universitas Indonesia dan Uniiversitas lainnya

Menurut Mangkunegara (2016) kinerja merupakan hasil kerja secara kualitas dan kuantitas yang dicapai oleh seorang pegawai dalam melaksanakan tugasnya sesuai dengan tanggung jawab yang diberikan padanya. Kinerja juga dapat diartikan sebagai tingkat pencapaian pelaksanaan suatu program kegiatan atau kebijakan dalam mewujudkan sasaran, tujuan, visi dan misi organisasi yang dituangkan dalam suatu perencanaan Strategis suatu organisasi (Moeheriono 2012). Sedangkan kinerja guru menurut Obilade didefinisikan sebagai tugas yang dilaksanakan pada priode tertentu dalam sistem sekolah, untuk mencapai tujuan organisasi (Adeyemi 2010). Dalam hal ini, kinerja guru merupakan kemampuan seoarang guru dalam melaksanakan tugas pembelajaran dan bertanggung jawab atas peserta didik di bawah bimbingannya dengan meningkatkan prestasi belajar peserta didik (Supardi 2012) dimana dalam proses pelaksanaan tugasnya ada kriteria tertentu yang harus dikerjakan oleh guru (Suharsaputra 2010) dengan demikian kinerja guru merupakan capaian atas kegiatan pengajaran yang telah ditetapkan sekolah baik secara kualitas maupun kuantitas dalam priode tertentu.

Berkaitan dengan kepentingan penilaian terhadap kinerja guru, penilaian kinerja harus memenuhi ukuran kinerja dilakukan sesuai dengan indikator kinerja sebagai alat ukurnya.Indikator tersebut meliputi kualitas hasil kerja, ketepatan waktu, inisiatif dalam menyelesaikan pekerjaan, adanya kemampuan untuk menyelesaikan pekerjaan dan cakap dalam komunikasi atau memiliki kemampuan dalam membina kerjasama dengan pihak lain (Mitchell 1982). Sedangkan menurut Uno (2012), penilaian kinerja dapat dilihat dari (1) kualitas kerja;(2) ketepatan/kecepatan kerja; (3) inisiatif dalam kerja; (4) kemampuan kerja; dan (5) komunikasi. Dalam penilaian kinerja guru, Georgia Department Of Education telah mengembangkan Teacher performance assessment instrument yang mencakup; (1) 
Rencana Pembelajaran atau biasa disebut dengan RPP; (Rencana Pelaksanaan Pembelajaran);

(2) Prosedur

Pembelajaran; dan (3) hubungan antar pribadi yang kemudian dimodifikasi oleh depdiknas menjadi Alat Penilaian Kemampuan Guru (APKG) dituliskan secara rinci dalam Permendiknas Nomor 63 Tahun 2013 tentang standar proses yang berisi kriteria minimal pelaksanaan proses pembelajaran yang mencakup (1) perencanaan proses pembelajaran; (2) pelaksanaan proses pembelajaran; dan (3) penilaian hasil belajar(Permendiknas 2016), sehingga berdasarkan acuan teori kinerjamengajar di atas, dalam penelitian ini penulis menggunakan acuan Permendiknas sebagai tinjauan untuk meninjau kinerja guru dalam mengajar di SMA Negeri 1 Makassar.

Banyak faktor yang mempengaruhi kinerja mengajar guru. Menurut Burhanudin Faktor yang mempengaruhi kinerja diantaranya adalah tingkat pendidikan guru, supervisi pengajaran, gaya kepemimpinan kepala sekolah (Burhanuddin, 2007) Sedangkan menurut Vroom mengemukakan suggested that performance is a function of ability and motivation as depicted in the formula; Performance F (ability x motivation). The effects of ability and motivation onperformance are not additive but multiplicative. People need both ability and motivation to perform well, and if either ability or motivation is zero there will be no effective performence (Armstrong 2009). Sedangkan menurut Blumberg dan Pringle (1982) bahwa rumusan kinerja adalah Kinerja= individual Atribut $x$ usaha kerja $x$ dukungan organisasi.

Dari sekian banyak faktor yang mempengaruhi kinerja guru.Supervisi pendidikan sebagai bagian dari dukungan organisasi dan motivasi sebagai bagian dari individual atribut merupkan beberapa faktor yang mempengaruhi kinerja guru. Oleh karenanya dalam peneliatan ini penulis tertarik untuk mengetahui sejauh mana kegiatan supervisi pendidikan dan motivasi kerja guru berpengaruh terhadap kinerja guru.

Kegiatan supervisi pendidikan memiliki pengaruh dan peranan penting dalam meningkatkan kinerja guru dalam mengajar. Kepala sekolah sebagai pemimpin pendidikan di sekolah memiliki peranan sebagai supervisor memiliki tanggung jawab untuk melakukan kegiatan supervisi agar dapat tercapai tujuan dari pendidikan. Peranan tersebut sebagaiamana yang dikemukakan oleh Murniati (2008) bahwa peran kepala 
sekolah sebagai (1) pendidik ;(2) supervisor;(3) pemimpin;(4) manajer; (5) admistrator; (6) invator; dan (7) motivator.

Supervisi secara etimologi berasal dari kata super dan visi yang memiliki arti melihat atau meninjau dari atas atau menilik dan menilai dari atas yang dilakukan oleh pihak atasan terhadap aktifitas, kreativitas, dan kinerja bawahan (Mulyasa 2003) Supervisi merupakan bantuan dalam pengembangan situasi belajar mengajar menjadi lebih baik dalam rangka meningkatkan mutu pendidikan (Arafat et al. 2020) sedangkan menurut Komariah supervisi dapat berarti pengawasan yang dilakukan oleh orang yang ahli/profesional dalam bidangnya sehingga dapat memberikan perbaikan dan peningkatan/pembinaan agar pemebelajaran dapat dilakukan ag dengan baik dan berkualitas, sehingga targetan atas capaian pendidikan bisa tercapai (2021)

Tujuan dari supervisi pendidikan menurut Franseth adalah memberikan bantuan terhadap program pendidikan melalui bermacam-macam cara sehingga kualitas kehidupan akan diperbaiki karenanya. Sedangkan Fred E.Ayer menganggap fungsi supervisi untuk memelihara program yang ada dengan sebaik-baiknya, sehingga ada perbaikan.
Secara lebih terang Le $\mathbf{J}$ Brucker menyatakan bahwa funsi utama supervisi modern menilai dan memperbaiki factorfactor yang mempengaruhi hasil belajar (Sahertian and Ida Aleida 2009).

Supervisi pendidikan menurut Rifai (1982) memiliki tujuh fungsi yaitu; fungsi kepemimpinan, inspeksi, penelitian, latihan dan pembimbingan, sumber dan pelayanan, koordinasi dan terakhir adalah evaluasi. Ametembum (1981) lebih ringkas dalam melihat fungsi dari supervisi dimana ia membaginya menjadi empat fungsi yaitu penelitian, penilaian perbaikan dan peningkatan. Sedangkan Sutisna (1983) melihat fungsi supervisi dalam empat hal berbeda yaitu (1) penggerak perubahan; (2) pelayanan untuk memajukan pengajaran; (3) keterampilan dalam hubungan manusia dan (4) kepemimpinan kooperatif. Namun secara ringkas fungsi dari supervisi yang utama adalah membantu sekolah yang sekaligus mewakili pemerintah dalam usaha mencapai tujuan pendidikan yaitu membantu perkembangan individu siswa (Pidarta 1992).

Dengan demikian kegiatan supervisi pendidikan sebagaimana yang telah dikemukakan para pakar di atas menunjukan bahwa guru membutuhkan bantuan dari kepala sekolah yang secara 
struktural dan fungsi untuk memberikan bantuan terhadap guru dalam memecahkan persoalan dan perbaikan kualitas pembelajaran secara sistematis, berkelanjutan dan komprehensif. Sehingga guru dalam proses pengajaran bisa meningkatkan kinerjanya guna mencapai tujuan pembelajaran.

Berkaitan dengan motivasi kerja, Kata 'motivasi' berasal dari kata "motif" yang dapat diartikan sebagai kekuatan yang terdapat dalam diri individu, yang menyebabkan individu tersebut berbuat atau berkehendak, sebuah keinginan atau kebutuhan yang melatar belakangi seseorang sehingga ia terdorong untuk bekerja (Usman 2006). Motivasi tidak dapat diamati secara langsung, tetapi motivasi dapat diinterpretasikan dalam tingkah laku yang bisa berupa rangsangan maupun dorongan yang memicu munculnya tindakan (Uno 2008). Menurut Hasibuan (2016) motivasi adalah pemberian daya penggerak yang menciptakan kegairahan kerja seseorang agar mereka mau bekerja sama, bekerja efektif dan terintegrasi dengan segala upayanya untuk mencapai kepuasan. Guru yang memiliki motivasi kerja yang tinggi akan senantiasa bekerja keras untuk mengatasi segala jenis permaslahan yang dihadapi dengan harapan mencapai hasil yang lebih baik (Mangkunegara 2016). Motivasi kerja guru memiliki dua dimensi yaitu; motivasi internal dan motivasi eksternal (Uno 2008). Sedangkan indikator untuk mengukur motivasi kerja guru sebagaimana yang dikemukakan Suryana (2020) meliputi (1) imbalan yang layak, dimana gaji yang diberikan lembaga dapat menentukan motivasi kerja guru; (2) kesempatan untuk promosi. Adanya kesempatan promosi jabatan yang diberikan lembaga kepada guru akan berdampak pada motivasi kerja guru; (3) memperoleh pengakuan, sebuah pengakuan terhadap kerja yang telah dilaksanakan guru akan memberikan peningkatan motivasi pada guru dalam bekerja dan (4) keamanan kerja, lingkungan sekolah yang nyaman dan kondusif bagi guru akan memotifasi guru secara maksimal dalam bekerja. Sedangkan menurut Chung dan Megginson (dalam Faustino 2003) mengemukakan bahwa motivasi kerja melibatkan dua faktor utama: (1) faktor individual, meliputi kebutuhan, tujuan, sikap dan kemampuan dan (2) faktor organisasional yang meliputi pembayaran gaji, keamanan pekerjaan, seseama pekerja, pengawasan, pujian dan pekerjaan itu sendiri. 
Dari uraian yang sudah dipaparkan pada bagian pendahuluan. Maka dirumuskan suatu permasalahan dalam pernyataan-pernyataan berikut; 1) Supervisi Pendidikan (X1) berpengaruh secara postif terhadap kinerja Guru (Y), 2) Motivasi Kerja Guru (X2) berpengaruh positif terhadap kinerja Guru (Y), 3) Supervisi Pendidikan dan Motivasi Kerja Guru berpengaruh secara positif terhadap Kinerja Guru (Y)

\section{B. METODE PENELITIAN}

Penelitian ini merupakan penelitian Ex post facto dimana penulis berusaha mengungkap hubungan amtara variabel Supervisi Pendidikan dengan variabel Motivasi Kerja Guru sebagai variabel bebas dan variabel Kinerja Guru sebagai Variabel terikat. Penelitian ini dilakukan di SMA Negeri 1 Makassar yang beralamat di J1. Gunung Bawakaraeng No. 53. RT/RW: 1/3 Kel. Gaddong Kec. Bontoala Kota Makassar provinsi Sulawesi Selatan. Dipilihnya SMA Negeri 1 Makassar, dengan dasar pertimbangan jumlah guru memenuhi persyaratan untuk dijadikan lokasi penelitian.Selain itu keterjangkauan lokasi penelitian dengan penulis.

Populasi dalam penelitian ini adalah segenap guru yang mengajar di SMA Negeri 1 Makassar dimana jumlah guru di sekolah tersebut sebanyak 64 guru.
Menurut Sugiyono (2008) sampel adalah bagian dari jumlah dan karakteristik yang dimiliki oleh populasi. Dalam menentukan populasi dalam penelitian ini, penulis menggunakan rumusan Arikunto (2003:104) jika jumlah populasi penelitian kurang dari 100 maka jumlah sampelnya diambil secara keseluruhan. Oleh karenanya dalam penelitian ini 62 guru di SMA Negeri 1 Makassar menjadi sampel dalam penelitian ini.

Metode pengumpulan data dalam penelitian ini menggunakan kuisioner atau angket untuk semua variabel dalam bentuk pertanyaan dan dilengkapi dengan jawaban. Skala instrumen yang digunakan adalah skala likert. Di mana skor tertinggi di tiap butir adalah 4 dan yang terendah adalah (Mardapi 2012). Instrumen kemudian diuji-cobakan agar kualitas instrumen bisa diketahui apakahvaliditas dan reliabilitasnya terpenuhi atau tidak. Baik-buruknya instrumen akan berpengaruh terhadap benar tidaknya data yang diperoleh. Sedangkan benar tidaknya sangat menentukan bermutu atautidaknya hasil penelitian (Arikunto 2003). Uji validitas dilakukan dengan menggunakan Pearson Product Moment Corelation dengan menggunakan bantuan program IBM SPSS Statistics 25.0.Suatu butir instrumen dikatakan valid jika nilai indeks 
validitasnya $\geq 0,3$ (Sugiyono 2008). Jika harga korelasi di bawah 0,3 maka butir instrumen dinyatakan tidak valid. Sedangkan uji reliabilitas yang bertujuan memperoleh instrumen yang benar-benar dapat dipercaya atau handal. Uji reliabilitas dilakukan setelah uji validitas di mana uji reliabilitas hanya dilakukan pada instrumen yang telah dianggap valid. Kriteria uji reliabilitas instrumen menggunakan rumus Cronbach's Alpha di mana suatu instrumen dinyatakan reliabel jika nilai Cronbach's Alpha lebih besar dari 0,60 maka instrumen dinyatakan reliabel atau handal. Setelah melakukan uji validitas dan reliabilitas, makainstrumen kuisioner dalam penelitian yang penulis kerjakan dianggap sudah melalui tahapan tahapan tersebut.

Untuk mengetahui pengaruh supervisi pendidikan dan motivasi kerja guru terhadap kinerja guru di SMA Negeri 1 Makassar, dimana variabel penelitiannya terdiri dari dua variabel bebas (independent Variabel) dan satu variabel terikat (dependent variabel),maka digunakan analisis statistik regresi linear berganda yang mencakup $t$-test dan $F$-test. Analisis tersebut diolah dengan menggunakan bantuan program IBM SPSS Statistics 25.0.

Sebelum melakukan uji regresi linear berganda, penulis melakukan uji persyaratan analisis dengan menggunakan uji normalitas, ujilinearitas dan uji multikolineritas. Uji normalitas dilakukan untuk mengetahui apakah dalam model regresi, variabel terdistribusi normal atau tidak. Uji normalitas menggunakan teknik analisis Kolmogorov- Smirnov. Teknik ini memakai program IBM SPSS Statistics 25.0. Jika nilai signifikasi lebih besar dari $0,05 \quad(\alpha>0,05)$ maka distribusi data dinyatakan normal(Ghozali 2006).

Hasil uji normalitas dalam penelitian ini sebagai berikut:

One-Sample Kolmogorov-Smirnov Test

\begin{tabular}{llr}
\hline $\mathrm{N}$ & & Unstandardized Residual \\
\hline Normal Parameters & & 64 \\
\cline { 2 - 3 } & Mean &, 0000000 \\
\cline { 2 - 3 } & Std. Deviation & 4,65181638 \\
\cline { 2 - 3 } & Absolute &, 081 \\
\cline { 2 - 3 } & Positive &, 081 \\
\cline { 2 - 3 } & Negative &,- 072 \\
\hline Test Statistic &, 081 \\
\hline Asymp. Sig. (2-tailed) &, $200^{\text {c,d }}$ \\
\hline a. Test distribution is Normal. & \\
b. Calculated from data. & \\
c. Lilliefors Significance Correction. & \\
d. This is a lower bound of the true significance. &
\end{tabular}


Sumber: data primer diolah, 2021

Hasil signifikasi yang diperoleh dalam uji normalitas teknik Kolomogrof Smirnov atas pengaruh Supervisi Akademik kepala sekolah $\left(\mathrm{X}_{1}\right)$ dan Motivasi Kerja $\left(\mathrm{X}_{2}\right)$ terhadap kinerja Guru (Y) sebesar 0,200 di mana 0,200 $>\alpha=$ 0,05. Dengan demikian Asumsi normalitas telah terpenuhi.

Uji linearitas dilakukan untuk mengetahui apakah data masing-masing variabel bebas memiliki hubungan linear dengan variabel terikat. Jika nilai Dari hasil uji linearitas diperoleh pengertian bahwa nilai Deviation from Linearity sebesar Sig 0,356 > Sig a 0,05 artinya terdapat hubungan linear antara variabel Supervisi Pendidikan $\left(\mathrm{X}_{1}\right)$ dan Motivasi Kerja $\left(\mathrm{X}_{2}\right)$ terhadap Variabel Kinerja Guru (Y)

Uji multikolineritas dilakukan untuk mengetahui besarnya nilaiinterkorelasi antara sesama variabel bebas.Gejala signifikansi pada lajur deviasidarilinearity $>0,05$, maka disimpulkan terdapat hubungan linear antar variabel. Hasil uji Linearitas dalam penelitian ini sebagai berikut:

\begin{tabular}{|c|c|c|c|}
\hline & ANOVA & Table & \\
\hline Kinerja & Between & (Combined) & .001 \\
\hline Guru* & Groups & Linearity & ,000 \\
\hline $\begin{array}{l}\text { Motivasi } \\
\text { Kerja }\end{array}$ & & $\begin{array}{l}\text { Deviation } \\
\text { from } \\
\text { Linearity }\end{array}$ & 356 \\
\hline & Within G & ups & \\
\hline & Total & & \\
\hline
\end{tabular}

multikolineritas dapat dilihat dari nilai tolerance dan variance inflation factor (VIF). Jika variabel bebas memiliki nilai Variance Inflation Factor (VIF) lebih kecil dari 10 (VIF < 10) dan nilai Tolerance di atas $10 \%(0,1)$ maka tidak terjadi gejala Multikolineritas. (Ghozali 2006). Berikut ini hasil uji multikolineritas menggunakan program IBM SPSS Statistics 25.0.

\section{Coefficients $^{\mathrm{a}}$}

\begin{tabular}{lrrr} 
& \multicolumn{3}{c}{ Collinearity Statistics } \\
Model & Tolerance & \multicolumn{1}{c}{ VIF } \\
\hline 1 Supervisi Pendidikan &, 790 & 1,267 \\
\cline { 2 - 3 } Motivasi Kerja &, 790 & 1,267 \\
\hline
\end{tabular}

a. Dependent Variable: Kinerja Guru

Sumber: data primer diolah, 2021 
Diketahu bahwa nilai Tolerance pada variabel Supervisi Pendidikan $\left(\mathrm{X}_{1}\right)$ dan Motivasi Kerja $\left(\mathrm{X}_{2}\right)$ sebesar 0. > 0.10 dan nilai Variance Inflation Factor (VIF) adalah < 10. Dengan demikian, dapat dinyatakan bahwa variabel Supervisi Pendidikan $\left(\mathrm{X}_{1}\right)$ dan Motivasi Kerja $\left(\mathrm{X}_{2}\right)$ terbebas dari gejala multikolineritas.

\section{HASIL DAN PEMBAHASAN}

\section{Analisis Regresi Linear berganda}

Analisis regresi berganda merupakan alat analisis peramalan nilai pengaruh dua variabel bebas atau lebih terhadap variabel terikat. Analisis ini digunakan untuk membuktikan ada atau tidaknya hubungan fungsi atau hubungan kausal antara variabel bebas tersebut dengan variabel terikat dengan rumusan $Y=\alpha+\beta_{1} X_{1}+\beta_{2} X_{2}+\ldots+\beta_{k} X_{k}+e$ (Riduwan 2013). Dalam penelitian ini analisis regresi linear berganda digunakan untuk mengetahui pengaruh supervisi pendidikan kepala sekolah $\left(\mathrm{X}_{\mathrm{I}}\right)$ dan Motivasi Kerja $\left(\mathrm{X}_{2}\right)$ secara bersama-sama terhadap kinerja guru (Y). Rumusnya adalah sebagai berikut;

$\mathrm{Y}=\alpha+\beta_{1} \mathrm{X}_{1}+\beta_{2} \mathrm{X}_{2}+\ldots+\beta_{\mathrm{k}} \mathrm{X}_{\mathrm{k}}+\mathrm{e}$

Keterangan;

$\mathrm{Y}=$ Kinerja Guru

$\alpha \beta_{1} \beta_{2}=$ Koefisien Regresi
$\mathrm{X}_{1} \mathrm{X}_{2}=$ Supervisi Pendidikan dan Motivasi kerja

e $=$ Kesalahan Pengganggu (Disturbance Terma) variabel lain yang tidak dimasukan dalam pembahasan

Pengujian Analisis Regresi linear berganda dalam penelitian ini menggunakan program IBM SPSS Statistics 25.0. sebagai berikut:

\section{Coefficients $^{\mathrm{a}}$}

\begin{tabular}{|c|c|c|c|c|c|}
\hline Model & $\begin{array}{r}\text { Unsta } \\
\text { iz } \\
\text { Coef }\end{array}$ & $\begin{array}{l}\text { ndard } \\
\text { ed } \\
\text { icient } \\
\text { Std. } \\
\text { Erro } \\
r\end{array}$ & $\begin{array}{c}\text { Standa } \\
\text { rdized } \\
\text { Coeffi } \\
\text { cients } \\
\text { Beta }\end{array}$ & $\mathrm{T}$ & Sig. \\
\hline $\begin{array}{l}1 \text { (Consta } \\
\text { nt) }\end{array}$ & $\begin{array}{r}20,6 \\
02\end{array}$ & $\begin{array}{r}13,7 \\
73\end{array}$ & & $\begin{array}{r}1,4 \\
96\end{array}$ & 140 \\
\hline $\begin{array}{l}\text { Supervi } \\
\text { si } \\
\text { Pendidi } \\
\text { kan }\end{array}$ & ,339 & 109 & ,360 & $\begin{array}{r}3,1 \\
08\end{array}$ & 003 \\
\hline $\begin{array}{l}\text { Motivas } \\
\text { i Kerja }\end{array}$ & ,444 & ,144 & ,357 & $\begin{array}{r}3,0 \\
86\end{array}$ & ,003 \\
\hline
\end{tabular}

a. Dependent Variable: Kinerja Guru

Sumber : data primer diolah, 2021

Berdasarkan hasil pengujian pada tabel di atas, maka dapaat dibentuk suatu persamaan regresi linear berganda, sebagai berikut;

$Y=20,602+0,339 X_{1}+0,444 X_{2}$

$\mathrm{Y}=$ Kinerja Guru

$\mathrm{X}_{1}=$ Supervisi Pendidikan

$\mathrm{X}_{2}=$ Motivasi Kerja

Berdasarkan hasil tersebut maka dapat diinterpretasikan bahawa bila variabel bebas (Supervisi Pendidikan $\mathrm{X}_{1}$ 
dan Motivasi Kerja $\mathrm{X}_{2}$ ) bernilai nol maka variabel terikat (Kinerja Guru Y) akan Constan di angka 20,602. Besarnya koefesien regresi $\beta_{1}$ adalah 0,339 .Hal ini menunjujukan bahwa dengan meningkatnya variabel $X_{1}$ maka akan meningkatkan variabel $\mathrm{Y}$, artinya peningkatan pada kegiatan Supervisi Pendidikan $\mathrm{X}_{1}$ akan meningkatkan Kinerja Guru sebesar 0,339. Besarnya koefesion regresi $\beta_{2}$ adalah 0,444 .Hal ini menunjukan bahwa dengan meningkatnya variabel $\mathrm{X}_{2}$ maka akan meningkatkan variabel $\mathrm{Y}$, artinya peningkatan pada Motivasi Kerja X2 akan meningkatkan Kinerja Guru sebesar 0,444. Dengan demikian kegiatan Supervisi Pendidikan $\left(\mathrm{X}_{1}\right)$ dan Motivasi Kerja $\left(\mathrm{X}_{2}\right)$ berpengaruh secara positif terhadap kinerja Guru (Y).

Untuk melihat seberapa kuat hubungan anatara variabel bebas (Supervisi Pendidikan $\mathrm{X}_{1}$ dan Motivasi Kerja $\mathrm{X}_{2}$ ) dan variabel terikat (Kinerja Guru Y) peneliti menggunakan Model Summary dariprogram IBM SPSS Statistics 25.0. dengan hasil sebagai berikut:

\begin{tabular}{|c|c|c|c|c|}
\hline \multicolumn{5}{|c|}{ Model Summary ${ }^{b}$} \\
\hline \multirow[b]{3}{*}{ Model } & \multirow[b]{3}{*}{$\mathrm{R}$} & \multirow{3}{*}{$\begin{array}{c}\mathrm{R} \\
\text { Square }\end{array}$} & \multirow{3}{*}{$\begin{array}{c}\text { Adjusted } \\
\text { R } \\
\text { Square }\end{array}$} & \multirow{3}{*}{$\begin{array}{l}\text { Std. Error } \\
\text { of the } \\
\text { Estimate }\end{array}$} \\
\hline & & & & \\
\hline & & & & \\
\hline 1 &, $613^{\mathrm{a}}$ & ,375 & ,354 & 4,730 \\
\hline
\end{tabular}

a. Predictors: (Constant), Motivasi Kerja, Supervisi Pendidikan

b. Dependent Variable: Kinerja Guru

Sumber : data primer diolah, 2021

Nila R pada tabel di atas menunjukan adanya hubungan antara variabel bebas dan terikat dengan interpretasi koefisennya sebagaimana dikemukakan oleh sugiyono(2008) sebagai berikut;

0,00-0,199= Sangat Rendah

0,20-0,399= Rendah

0,40- 0,599= Sedang

0,60- 0,799= Kuat

0.80-1,000 = Sangat Kuat

Besaran nilai korelasi/hubungan (R) yang dijelaskan pada tabel Model Summary di atas adalah 0,613 (R). Artinya hubungan kegiatan Supervisi Pendidikan $\left(\mathrm{X}_{1}\right)$ dan Motivasi Kerja $\left(\mathrm{X}_{2}\right)$ terhadap Kinerja Guru (Y) memiliki korelasi kuat. Sedangkan besarnya koefisien determinasi atau kontribusi variabel bebas (Supervisi Pendidikan $X_{1}$ dan Motivasi Kerja $X_{2}$ ) terhadap variabel terikat (Kinerja Guru Y) ditunjukkan pada kolom nilai $\mathrm{R}$ Square $\left(\mathrm{R}^{2}\right)$ dengan rumus $\mathrm{KP}=\mathrm{R}^{2} \mathrm{X} 100 \%$. Nilai $\mathrm{R}$ Square $\left(\mathrm{R}^{2}\right)$ pada tabel Model Summary adalah $\mathrm{KP}=0,375 \times 100 \%=37,5 \%$.Nilai $\mathrm{R}$ Square $\left(\mathrm{R}^{2}\right)=0,375$ menunjukan bahwa variabel Supervisi Pendidikan $\left(\mathrm{X}_{1}\right)$ dan Motivasi Kerja $\left(\mathrm{X}_{2}\right)$ menjelaskan variabel kinerja guru (Y) sebesar 37,5\%. 62,5\% 
lainnya dijelaskan oleh faktor lain yang tidak termasuk dalam penelitian ini.

Untuk mengetahui besaran pengaruh variabel Supervisi Pendidikan $\left(\mathrm{X}_{1}\right)$ dan Motivasi Kerja $\left(\mathrm{X}_{2}\right)$ terhadap variabel kinerja guru (Y) maka dilakukan uji koefisien regresi secara simultan (UjiF)dengan dasar keputusan sebagai berikut: Jika $\mathrm{F}_{\text {Hitung }}>\mathrm{F}$ Tabel Maka $\mathrm{H}_{0}$ ditolak dan $\mathrm{H}_{1}$ diterima
Jika $\mathrm{F}_{\text {Hitung }}<\mathrm{F}$ Tabel Maka $\mathrm{H}_{0}$ diterima dan $\mathrm{H}_{1}$ ditolak

Jika Sig. F $<0,05$ Maka $\mathrm{H}_{0}$ ditolak dan $\mathrm{H}_{1}$ diterima

Jika Sig. $\mathrm{F}>0,05 \mathrm{Maka}_{0}$ diterima dan $\mathrm{H}_{1}$ ditolak

Hasil uji-F pada penelitian ini dengan mengunakan bantuan program IBM SPSS Statistics 25.0. dengan hasil sebagai berikut:

ANOVA $^{\mathrm{a}}$

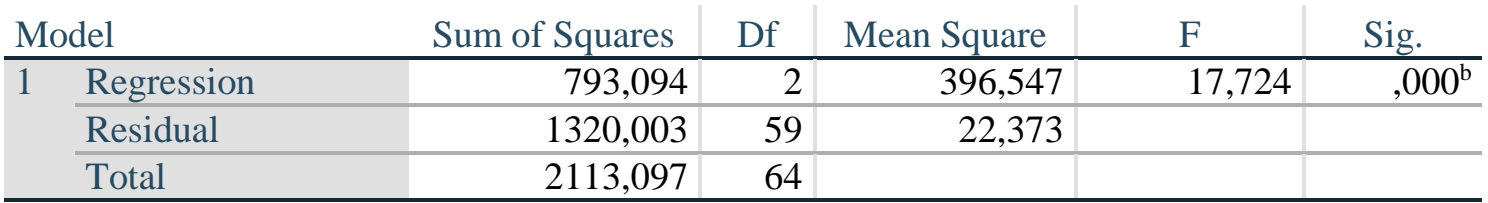

a. Dependent Variable: Kinerja Guru

b. Predictors: (Constant), Motivasi Kerja, Supervisi Pendidikan

Sumber: data primer diolah, 2021Pada

Tabel ANOVA di atas diketahui

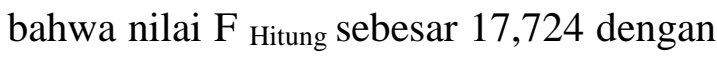
nilaiSig. F sebesar 0.000. di mana nila F Hitung $(17,724)$ lebih besar daripada $\mathrm{F}$ Tabel(3.15) dan nilai Sig. F lebih kecil dari 0,05 yang berariti bahwa variabel Supervisi Pendidikan $\mathrm{X}_{1}$ dan Motivasi Kerja $\mathrm{X}_{2}$ secara simultan berpengaruh terhadap Kinerja Guru (Y).

Setelah melakukan pengujian secara simultan (Uji-F) kemudian penulis melakukan pengujian secara parsial (UjiT) untk mengetahui apakah masing masing variabel bebas yaitu variabel Supervisi Pendidikan $\mathrm{X}_{1}$ dan Motivasi Kerja $\mathrm{X}_{2}$ secara parsial berpengaruh signifikan terhadap Kinerja Guru (Y) dengan dasar keputusan sebagai berikut

Jika $\mathrm{T}_{\text {Hitung }}>\mathrm{T}_{\text {Tabel }}$ Maka $\mathrm{H}_{0}$ ditolak dan $\mathrm{H}_{1}$ diterima

Jika $\mathrm{T}_{\text {Hitung }}>\mathrm{T}_{\text {Tabel }}$ Maka $\mathrm{H}_{0}$ diterima dan $\mathrm{H}_{1}$ ditolak

Jika Sig. $\mathrm{T}<0,05$ Maka $\mathrm{H}_{0}$ ditolak dan $\mathrm{H}_{1}$ diterima

Jika Sig. $\mathrm{T}>0,05$ Maka $\mathrm{H}_{0}$ diterima dan $\mathrm{H}_{1}$ ditolak

Untuk hasil uji-T pada penelitian ini dengan mengunakan bantuan program IBM SPSS Statistics 25.0. Dengan hasil sebagai berikut:

\section{Coefficients $^{\mathrm{a}}$}

\begin{tabular}{l|c|c|c} 
Model $\quad$ Unstandardized Coefficients & $\begin{array}{c}\text { Standardized } \\
\text { Coefficients }\end{array}$ & $\mathrm{T}$ & Sig.
\end{tabular}




\begin{tabular}{ll|r|r|r|r|r} 
& \multicolumn{2}{c}{ B } & Std. Error & Beta & & \\
\hline \multirow{2}{*}{1} & 20,602 & 13,773 & & 1,496 &, 140 \\
\cline { 2 - 7 } & (Constant) &, 339 &, 109 &, 360 & 3,108 &, 003 \\
\cline { 2 - 8 } & Supervisi Pendidikan &, 444 &, 144 &, 357 & 3,086 &, 003 \\
\hline
\end{tabular}

a. Dependent Variable: Kinerja Guru

Sumber: data primer diolah, 2021

Pada tabel Coefficients di atas diketahui bahwa nilai $\mathrm{T}_{\text {Hitung }}$ untuk variabel Supervisi Pendidikan sebesar 3,108 dengan tingkat Sig. T sebesar 0.003. di mana nilai $\mathrm{T}_{\text {Hitung }}(3,108)$ lebih besar daripada $\mathrm{T}_{\text {Tabel }}(1,998)$ dan nilai Sig. $\mathrm{F}$ lebih kecil dari 0,05 yang berariti bahwa variabel Supervisi Pendidikan $\left(\mathrm{X}_{1}\right)$ seacara parsial berpengaruh secara signifikan terhadap kinerja guru dan untuk Motivasi Kerja $\left(\mathrm{X}_{2}\right)$ nilai $\mathrm{T}$ Hitung sebesar 3,086 dengan tingkat Sig. T sebesar 0.003 . dimana nilai $\mathrm{T}_{\text {Hitung }}(3,086)$ lebih besar daripada $\mathrm{T}_{\text {Tabel }}(1,998)$ dan nilai Sig. $\mathrm{T}$ lebih kecil dari 0,05 yang berariti bahwa variabel Motivasi Kerja $\left(\mathrm{X}_{2}\right)$ secara partial berpengaruh signifikan terhadap Kinerja Guru (Y).

\section{KESIMPULAN DAN SARAN}

Hasil Penelitian menunjukan bahwa terdapat pengaruh positif dan signifikan dari supervisi pendidikan Kepala Sekolah dan Motivasi Kerja Guru terhadap Kinerja Guru di SMA Negeri 1 Makassar baik secara parsial maupun simultan dengan persamaan regresi $\mathrm{Y}=20,602+0,339 \mathrm{X}_{1}+$ $0,444 X_{2}$ Peningkatan pada kegiatan Supervisi Pendidikan $\mathrm{X}_{1}$ akan meningkatkan Kinerja Guru sebesar 0,339 dan peningkatan pada Motivasi Kerja $\mathrm{X}_{2}$ akan meningkatkan Kinerja Guru sebesar 0,444. Besaran nilai korelasi/hubungan $(\mathrm{R})$ Supervisi Pendidikan $\left(\mathrm{X}_{1}\right)$ dan Motivasi Kerja $\left(\mathrm{X}_{2}\right)$ dengan Kinerja Guru $(\mathrm{Y})$ adalah 0,613 (R) di mana hubungan tersebut bersifat kuat. Nilai koefisien Determinasi R Square $\left(\mathrm{R}^{2}\right)$ sebesar 0,375 . Hal tersebut menunjukan bahwa variabel Supervisi Pendidikan $\left(\mathrm{X}_{1}\right)$ dan Motivasi Kerja $\left(\mathrm{X}_{2}\right)$ dapat menjelaskan variabel kinerja guru (Y) sebesar $37,5 \%$ sedangkan $62,5 \%$ dijelaskan oleh faktor lain yang tidak termasuk dalam penelitian ini. Secara simultan (Uji-F) Supervisi Pendidikan $\left(\mathrm{X}_{1}\right)$ dan Motivasi Kerja $\left(\mathrm{X}_{2}\right)$ memiliki pengaruh signifikan terhadap Kinerja Guru (Y) dengan nilai $\mathrm{F}$ Hitung $(17,724)$ lebih besar daripada $F$ Tabel (3.15) dan nilai Sig. F lebih kecil dari 0,05. Dan berdasarkan Uji-T masing-masing variabel bebas dariSupervisi Pendidikan (X1) dan Motivasi Kerja $\left(\mathrm{X}_{2}\right)$ memiliki pengaruh signifikan terhadap Kinerja Guru dengan besaran $\mathrm{T}$ hitung untuk Supervisi Pendidikan $\left(\mathrm{X}_{1}\right)$ sebesar $(3,108)$ dan Motivasi Kerja $\left(\mathrm{X}_{2}\right)$ sebesar $(3,086)$. 
Dengan demikian dapat disimpulkan bahwa supervisi pendidikan yang dilakukan oleh Kepala Sekolah berpengaruh positif dan signifikan terhadap kinerja guru di SMA Negeri 1 Makassar. Artinya semakin baik supervisi pendidikan yang dilakukan oleh Kepala Sekolah akan meningkatkan kinerja guru. Sebaliknya, jika supervisi pendidikan yang diberikan kepala sekolah buruk maka kinerja guru jugatidak baik atau kurang optimal.

Motivasi Kerja Guru berpengaruh positif dan signifikan terhadap kinerja guru di SMA Negeri 1 Makassar. Artinya semakin baik Motivasi Kerja Guru akan meningkatkan kinerja guru. Begitupun sebaliknya jika Motivasi Kerja Guru buruk maka akan mebuat kinerja guru tidak baik atau kurang optimal.

Supervisi pendidikan yang dilakukan oleh Kepala Sekolah dan Motivasi Kerja Guru secara bersamaan berpengaruh positif dan signifikan terhadap kinerja guru di SMA Negeri 1 Makassar. Artinya semakin baik supervisi pendidikan yang dilakukan oleh Kepala Sekolah dan motivasi kerja guru maka akan meningkatkan kinerja guru. Begitupun sebaliknya jika supervisi pendidikan yang diberikan kepala sekolah buruk dan motivasi kerja guru buruk maka akan mebuat kinerja guru tidak baik atau kurang optimal.

\section{DAFTAR PUSTAKA}

Adeyemi, T. O. 2010. "Principals Leadership Styles and Teachers Job Performance in Senior Secondary Schools in Ondo State, Nigeria." International Journal of Educational Administration and Policy Studies 2(6):83-91.

Ametembun, N. A. 1981. Guru Dalam Administrasi Sekolah. Bandung: IKIP Bandung.

Arafat, Yasir, Happy Fitria, Kompetensi Profesional, and Kinerja Guru. 2020. "Pengaruh Supervisi Akademik Dan Kompetensi Profesional Guru Terhadap Kinerja Guru Di Sekolah Menengah Atas Negeri Di Kecamatan Tanjung Raja." 9(1).

Arikunto, Suharsimi. 2003. Manajemen Penelitian. Jakarta: Rineke Cipta.

Armstrong, Michael. 2009. Armstrong's Handbook of Performance Management: An Evidence-Based Guide to Delivering High Performance. London: Kogan Page Publishers.

Blumberg, Melvin, and Charles D. Pringle. 1982. "The Missing Opportunity in Organizational Research: Some Implications for a Theory of Work Performance." Academy of Management Review 7(4):560-69.

Burhanuddin, and Dkk. 2007. Supervisi Pendidikan Dan Pengajaran: Konsep, Pendekatan, Dan Penerapan Pembinaan Profesional. Malang: Rosindo.

Faustino, Cardoso Gomes. 2003. "Manajemen Sumber Daya Manusia." Yogyakarta: Penerbit Andi.

Ghozali, Imam. 2006. "Analisis Multivariate Lanjutan Dengan Program SPSS." Semarang: Badan 
Penerbit Universitas Diponegoro 105.

Hasibuan, Malayu S. P., and H. Malayu S. P. Hasibuan. 2016. Manajemen Sumber Daya Manusia. Bumi Aksara.

Komariah, Aan. 2021. "Administrasi Pendidikan."

Mangkunegara, A. A. Anwar Prabu. 2016. Manajemen Sumber Daya Manusia Perusahaan. Bandung: PT. Remaja Rosdakarya.

Mardapi, Djemari. 2012. "Pengukuran Penilaian Dan Evaluasi Pendidikan." Yogyakarta: Nuha Medika 45.

Marie-Helene, Doumet. 2019. "Education at a Glance: OECD Indicators." 1-5.

Mitchell, Terence R. 1982. People in Organizations: An Introduction to Organizational Behavior. New York: New York: McGraw-Hill.

Moeheriono, Edi, and Dr M. Si. 2012. "Pengukuran Kinerja Berbasis Kompetensi." Jakarta: Raja Grafindo Persada.

Mulyasa, Enco. 2003. Menjadi Kepala Sekolah Profesional: Dalam Konteks Menyukseskan MBS Dan $K B K$. Remaja Rosdakarya.

Mulyasa, Enco, and Mukhlis. 2007. Standar Kompetensi Dan Sertifikasi Guru. Remaja Rosdakarya.

Murniati, A. R. 2008. Manajemen Stratejik: Peran Kepala Sekolah Dalam Pemberdayaan. Perdana Publishing.

Olaleye, Florence Oluremi. 2013. "Improving Teacher Performance Competency Through Effective Human Resource Practices in Ekiti State Secondary Schools." Singaporean Journal of Business , Economics and Management Studies 1(11):125-32.

doi:
$10.12816 / 0003819$.

Permendiknas. 2016. "Tahun 2016 Tentang Standar Proses Pendidikan Dasar Dan Menengah." Jakarta: Depdiknas.

Pidarta, Made. 1992. Pemikiran Tentang Supervisi Pendidikan. Bumi Aksara.

Riduwan. 2013. Rumus Dan Data Dalam Analisis Statistika. yogyakarta: Alfabeta.

Rifai, M. 1982. "Pengantar Administrasi Dan Supervisi Pendidikan." Bandung: Baru.

Sahertian, Piet A., and Ida Aleida. 2009. "Supervisi Pendidikan." Jakarta: Rinika Cipta, Cet. IV.

Sisdiknas, Undang-Undang. 2003. "UU RI No. 20 Tahun 2003.” Jakarta: Sinar Grafika.

Sugiyono. 2008. Metode Penelitian Pendidikan:(Pendekatan

Kuantitatif, Kualitatif Dan $R \& D$ ). Alfabeta.

Suharsaputra, Uhar. 2010. "Administrasi Pendidikan, Bandung: PT.” Rafika Aditama.

Supardi, Supardi. 2012. "Kinerja Guru."

Suryana, A. A. 2020. "Supervisi Pendidikan Dalam Pengembangan Proses Pengajaran."

Sutisna, Oteng. 1983. Administrasi Pendidikan: Dasar Teoritis Untuk Praktek Profesional. Bandung: Angkasa,.

Uno, Hamzah B. 2012. Teori Kinerja \& Pengukurannya. Jakarta: Bumi Aksara.

Uno, Hamzah b. 2008. "Teori Motivasi \& Pengukurannya." Bumi Aksara 22. Retrieved January 9, 2021

Usman, Husaini. 2006. "Manajemen: Teori, Praktik, Dan Riset Pendidikan." Jakarta: Bumi Aksar 